\title{
Drought stress had a predominant effect over heat stress on three tomato cultivars subjected to combined stress
}

Rong Zhou ${ }^{1,2,3 \dagger}$, Xiaqing Yu ${ }^{3 \dagger}$, Carl-Otto Ottosen ${ }^{4}$, Eva Rosenqvist ${ }^{5}$, Liping Zhao ${ }^{1,2}$, Yinlei Wang ${ }^{1,2}$, Wengui Yu ${ }^{1,2}$, Tongmin Zhao ${ }^{1,2^{*}}$ and Zhen $\mathrm{Wu}^{3^{*}}$

\begin{abstract}
Background: Abiotic stresses due to environmental factors could adversely affect the growth and development of crops. Among the abiotic stresses, drought and heat stress are two critical threats to crop growth and sustainable agriculture worldwide. Considering global climate change, incidence of combined drought and heat stress is likely to increase. The aim of this study was to shed light on plant growth performance and leaf physiology of three tomatoes cultivars ('Arvento', 'LA1994' and 'LA2093') under control, drought, heat and combined stress.

Results: Shoot fresh and dry weight, leaf area and relative water content of all cultivars significantly decreased under drought and combined stress as compared to control. The net photosynthesis and starch content were significantly lower under drought and combined stress than control in the three cultivars. Stomata and pore length of the three cultivars significantly decreased under drought and combined stress as compared to control. The tomato 'Arvento' was more affected by heat stress than 'LA1994' and 'LA2093' due to significant decreases in shoot dry weight, chlorophyll a and carotenoid content, starch content and NPQ (non-photochemical quenching) only in 'Arvento' under heat treatment. By comparison, the two heat-tolerant tomatoes were more affected by drought stress compared to 'Arvento' as shown by small stomatal and pore area, decreased sucrose content, $\Phi_{\text {PSII }}$ (quantum yield of photosystem II), ETR (electron transport rate) and qL (fraction of open PSII centers) in 'LA1994' and 'LA2093'. The three cultivars showed similar response when subjected to the combination of drought and heat stress as shown by most physiological parameters, even though only 'LA1994' and 'LA2093' showed decreased Fv/F (maximum potential quantum efficiency of photosystem II), ФPSII, ETR and qL under combined stress.

Conclusions: The cultivars differing in heat sensitivity did not show difference in the combined stress sensitivity, indicating that selection for tomatoes with combined stress tolerance might not be correlated with the single stress tolerance. In this study, drought stress had a predominant effect on tomato over heat stress, which explained why simultaneous application of heat and drought revealed similar physiological responses to the drought stress. These results will uncover the difference and linkage between the physiological response of tomatoes to drought, heat and combined stress and be important for the selection and breeding of tolerant tomato cultivars under single and combine stress.
\end{abstract}

Keywords: Tomato, Drought stress, Heat stress, Photosynthesis, Chlorophyll fluorescence

\footnotetext{
* Correspondence: tmzhaomail@163.com; zpzx@njau.edu.cn

${ }^{\dagger}$ Equal contributors

${ }^{1}$ Institute of Vegetable Crop, Jiangsu Academy of Agricultural Science,

Nanjing, Jiangsu, China

${ }^{3}$ College of Horticulture, Nanjing Agricultural University, Nanjing, Jiangsu,

China

Full list of author information is available at the end of the article
} 


\section{Background}

Abiotic stresses caused by environmental factors could adversely affect the growth and development of crops [1]. Crops respond to the abiotic stresses with various modifications on morphological, cellular, physiological, biochemical and molecular level [2-4]. In the last decade, lots of studies focused on the response of crops to a single stress $[3,5,6]$. However, several abiotic stresses usually occur concurrently and crops are always subjected to a combination of different abiotic stresses in the field [1, 7]. Among the abiotic stresses, drought and heat stress are two critical threats to crop growth and sustainable agriculture worldwide [8-10]. Drought stress as a consequence of insufficient rainfall or deficient soil moisture might induce various biochemical, physiological and genetic responses in plants, which severely restricted crop growth $[11,12]$. Heat stress due to global warming has increasingly deleterious effect on crop production and heat stress is quite common for the crops cultivated through summer [13]. Heat stress is frequently associated with drought stress in field conditions [14], which makes necessary the study of crops responding to combined heat and drought stress.

Tomato (Solanum lycopersicum L., formerly Lycopersicon esculentum Mill.) is one of the most important vegetables in the world. Many studies have described the physiological response of tomatoes to drought and heat stress applied individually $[4,15-18]$. The combined effect of drought and heat has been mainly studied in chickpea [10], tobacco [19], Arabidopsis [20, 21] and wheat $[2,22]$. Response of plants to combined drought and heat could not be directly extrapolated from the response of plants to the individual stresses [19-21, 23]. Tomato often encounter the combination of drought and heat stress during its cultivation. However, effect of the combined drought and heat stress on tomato and the relationship between the physiological responses of tomatoes to single and combined stress remained unclear.

Compared to individual stress, combined stress of drought and heat induced the expression of HSPs in wheat [22] and induced specific proteins in wild barley [24]. There could be different responsive mechanism of plants to combined stress with individual stress [7, 21, 23]. Under drought stress, inhibition of plant photosynthesis by stomatal closure caused the unbalance between light reaction and Calvin-Benson cycle as a consequence of limited $\mathrm{CO}_{2}$ diffusion into the leaf [25]. By comparison, heat stress restrained plant photosynthesis mainly through affecting biochemical reactions [26, 27]. Heat tolerant wheat cultivars could maintain high rates of photosynthesis and stomatal conductance during heat stress, while decreased rates of photosynthesis induced decreased stomatal conductance in sensitive cultivars [28]. Photosynthetic products, namely sugars, specifically accumulated during the combination of drought and heat stress [20].

Photosystem II (PSII) is a sensitive component to heat stress [29]. Chlorophyll fluorescence is an efficient and non-destructive technique to measure the photochemical efficiency of PSII and thereby detect the damage of stress in PSII [30]. The maximum potential quantum efficiency of PSII $\left(\mathrm{F}_{\mathrm{v}} / \mathrm{F}_{\mathrm{m}}\right)$ provides an estimate of the maximum quantum efficiency of PSII, which is primarily affected by heat stress [4, 31].

The aim was to (i) dissect growth performance and physiological responses of tomatoes under drought, heat and combined stress in terms of leaf relative water content, pigment content, stomatal characteristics, photosynthesis, carbohydrate content and chlorophyll fluorescence; (ii) compare the tolerance of three tomato cultivars to combined stress. We hypothesized that (1) the tomatoes showed heat tolerance might not show the combined stress tolerance; (2) combined drought and heat stress might cause specific response on tomatoes than single stress, or similar response to single stress when one of the single stress played a predominant role on tomato. This study will help us to uncover the difference and linkage between the physiological response of tomatoes to drought, heat and combined stress and provide us theoretical basis for improving tomato tolerance to more instable climates.

\section{Methods}

\section{Plant material and growth condition}

One common greenhouse tomato cultivar 'Arvento' (Solanum lycopersicum) (Rijk Zwaan Nederland B.V, De Lier, Netherlands) and two heat-tolerant tomatoes based on our previous research including 'LA1994' (S. lycopersicum) and 'LA2093' (S. pimpinellifolium) (Tomato genetics resource centre, TGRC, University of California, CA, USA) were used [4]. Seeds were sown in a plug tray. After 18 days, the seedlings were transferred to plastic pots (11-cm diameter, $9 \mathrm{~cm}$ height) with commercial sphagnum substrate (Pindstrup 2; Pindstrup Mosebrug A/S, Ryomgaard, Denmark). The seedlings were grown in a greenhouse under long-day conditions with supplementary light provided by SON-T lamps (Phillips, Eindhoven, Netherlands). The average daytime photosynthetic photon flux density (PPFD) was $250-350 \mu \mathrm{mol} \mathrm{m} \mathrm{m}^{-2} \mathrm{~s}^{-1}$ in the greenhouse with $60 \pm 5 \%$ relative humidity $(\mathrm{RH})$ and $400 \mathrm{ppm} \mathrm{CO}_{2}$. Air temperature was $24 \pm 3{ }^{\circ} \mathrm{C}$ during the day and $18 \pm 3{ }^{\circ} \mathrm{C}$ during the night. The seedlings were irrigated by flooding the benches every morning for 10 min with a full nutrient solution (PH 6.0, EC $2.34 \mathrm{mS}$ $\mathrm{cm}^{-1}$, N $185 \mathrm{mg} \mathrm{L}^{-1}$, P $27 \mathrm{mg} \mathrm{L}^{-1}, \mathrm{~K} 171 \mathrm{mg} \mathrm{L}^{-1}, \mathrm{Mg}$ $20 \mathrm{mg} \mathrm{L}^{-1}$ and full micro nutrients). 
In order to reduce the complexity of interactions between genetic and environmental effects on phenotype, the study was conducted in climate chamber, where the onset of some abiotic stresses can be clearly defined, such as increasing the temperature and withdrawing the irrigation without the influence of rainfall. The 21-day-old uniformly sized seedlings were transferred to climate chambers (MB teknik, Brøndby, Denmark). Environmental parameter settings of the chambers were $26 / 20{ }^{\circ} \mathrm{C}$ for day/night, $60 \% \mathrm{RH}$, $400 \mathrm{ppm} \mathrm{CO}_{2}$, a 14-h photoperiod with $300 \pm$ $20 \mu \mathrm{mol} \mathrm{m} \mathrm{m}^{-2} \mathrm{~s}^{-1}$ PPFD. The seedlings were irrigated with the full nutrient solution once every day for $10 \mathrm{~min}$. The 25-day-old seedlings were randomly divided into four groups with 12 plants per cultivar for each treatment. The experiment included four treatments: (1) control, $26 / 20{ }^{\circ} \mathrm{C}$ (day/night) with three times of irrigation every day; (2) heat stress, $32 / 26{ }^{\circ} \mathrm{C}$ (day/night) with three times of irrigation every day; (3) drought stress, $26 / 20{ }^{\circ} \mathrm{C}$ (day/night) without irrigation; (4) combination of heat and drought stress, $32 / 26{ }^{\circ} \mathrm{C}$ (day/night) without irrigation. The treatments lasted for five days since the tomatoes under single drought and combine stress showed significant phenotype change such as leaf wilting on day 4, which become severe on day 5 during the preliminary experiment.

\section{Destructive harvest and leaf temperature}

Plant height and internode length was measured with a ruler on day 4. Leaf number was counted and leaf angle between the leaf and main stem was measured with a protractor on day 4 . The plants were harvested on day 5 . Leaf area was immediately measured with a leaf area meter (model 3100, LI-COR, Lincoln, Nebraska, USA) after the harvest. Shoot fresh weight (above cotyledonary node) was measured by cutting the seedling from the cotyledonary node. The shoot dry weight was measured after drying the shoot in an oven at $85{ }^{\circ} \mathrm{C}$ for $48 \mathrm{~h}$. There were four replications from four plants per cultivar and per treatment for the measurements of plant height, internode length, leaf number, leaf angle, leaf area and shoot fresh and dry weight.

In situ leaf temperature of four plants per cultivar and per treatment was measured with a Raynger $3 i$ infrared gun (Raytek, Santa Cruz, CA, USA) during the 10th hours of the light period on day 2 and day 4. Average leaf temperature of the two days was the final result.

\section{Relative water content}

One leaflet from the first fully expanded leaf of four plants per cultivar and per treatment was cut from a plant on day 5. Fresh weight (FW) of the leaflet was immediately measured after cutting. Then, the leaflet was immersed in dd- $\mathrm{H}_{2} \mathrm{O}$ in a petri dish and incubated under normal room temperature. After four hours, the leaflet was taken out, properly wiped to remove the water on the surface of the blade and weighed to obtain turgid weight (TW). Afterwards, the leaflet was put in a drying oven for $24 \mathrm{~h}$ and weighed to obtain dry weight $(\mathrm{DW})$. Relative water content $(\mathrm{RWC}$ in $\%)=[(\mathrm{FW}$ $\mathrm{DW}) /(\mathrm{TW}-\mathrm{DW})] * 100$.

\section{Chlorophyll content}

Pigment content was determined using the method of Wintermans and De Mots (1965) [32]. Two leaf disks (1.54 $\mathrm{cm}^{2}$ for each) were punched out from the first fully expanded leaf of four plants per cultivar and per treatment without the main vein using a cork borer, immersed in $10 \mathrm{~mL} 95 \%$ cold ethanol and incubated in $4{ }^{\circ} \mathrm{C}$ in darkness for $48 \mathrm{~h}$. The absorption was measured at 470, 649 and $665 \mathrm{~nm}$ using a UV-VIS spectrophotometer (Shimadzu UV-1700, Kyoto, Japan). Chlorophyll a (Chl a), chlorophyll b (Chl b) and carotenoid (Car) contents per unit area $\left(\mathrm{mg} / \mathrm{cm}^{2}\right)$ were calculated by the formula Chl $\mathrm{a}=\left(13.95 \times \mathrm{A}_{665}-6.88 \times\right.$ $\left.\mathrm{A}_{649}\right) / 1.54$, Chl $\mathrm{b}=\left(24.96 \times \mathrm{A}_{649}-7.32 \times \mathrm{A}_{665}\right) / 1.54$ and $\mathrm{Car}=\left(10^{3} \times \mathrm{A}_{470}-2.05 \times \mathrm{Chl} \quad \mathrm{a}-114.8 \times \mathrm{Chl} \quad \mathrm{b}\right) / 1.54$, respectively.

\section{Stomatal anatomy}

Abaxial side of the first fully expanded leaf without the main vein was used for impression of stomata with elite HD+ (Zhermack, Badia Polesine, Italy) using the method of Giday et al. [33]. Four leaflets from four plants per cultivar and per treatment were sampled on day 5. Six non-overlapping fields of each sample were taken pictures using a magnification of $19.2 \times$. Stomatal density was accessed on 24 fields per treatment. The length, width and area of stomata and pore were measured on 48 randomly chosen stomata per treatment (two stomata per field).

\section{Gas exchange and carbohydrate content}

The temperature response curve for net photosynthetic rate $\left(P_{\mathrm{N}}\right)$, intracellular $\mathrm{CO}_{2}$ concentration $\left(C_{\mathrm{i}}\right)$, stomatal conductance $\left(g_{\mathrm{s}}\right)$ and transpiration rate $(E)$ was measured using a portable photosynthesis system (CIRAS-2, PP Systems, Amesbury, USA). Measurement of four plants per cultivar and per treatment started day 4 at a temperature of $24{ }^{\circ} \mathrm{C}$ followed by $26{ }^{\circ} \mathrm{C}, 28{ }^{\circ} \mathrm{C}, 30{ }^{\circ} \mathrm{C}, 32{ }^{\circ} \mathrm{C}, 34{ }^{\circ} \mathrm{C}$ and $36{ }^{\circ} \mathrm{C}$. Light intensity was $300 \mu \mathrm{mol} \mathrm{m} \mathrm{m}^{-2} \mathrm{~s}^{-1}$ provided by LED light source (PP Systems, Amesbury, USA). The first fully expanded leaf was placed in situ in a cuvette $\left(1.7 \mathrm{~cm}^{2}\right)$ and the measurements were recorded every $10 \mathrm{~s}$ until $P_{\mathrm{N}}$ and $g_{\mathrm{s}}$ reached a steady state. Average of the last five values was used as the final result for each temperature level. To maintain the vapor pressure deficit (VPD) at 1.0-3.4 $\mathrm{kPa}$, a moist cloth was 
placed on the water vapor equilibrator of the CIRAS-2 when the VPD was above $2.0 \mathrm{kPa}$; the air was dehumidified when the VPD was below $0.8 \mathrm{kPa}$.

During the last $2 \mathrm{~h}$ of the light period on day 5 , the first fully expanded leaf was harvested, immediately frozen in liquid nitrogen and stored at $-80{ }^{\circ} \mathrm{C}$. The samples of four plants per cultivar and per treatment were freeze-dried (Gamma 1-20, LMC-1, Struers., Denmark) for three days, ground in a mixer mill (MM200, Retsch Inc., Haan, Germany) and weighed. The content of glucose, fructose, sucrose and starch was extracted and measured as described by Zhou et al. [4].

\section{Chlorophyll fluorescence}

Chlorophyll fluorescence measurement was performed on the first fully expanded leaf of four plants per cultivar and per treatment on day 4. For quenching analysis, the seedling was dark adapted for $20 \mathrm{~min}$ in a dark room. The $F_{v} / F_{m}$ was measured with a MINI-PAM (Walz, Effeltrich, Germany) operated with the WinControl software. $\Phi_{\mathrm{PSII}}=\mathrm{F}_{\mathrm{q}}{ }^{\prime} / \mathrm{F}_{\mathrm{m}}{ }^{\prime}$ (quantum yield of PSII), $\mathrm{q}_{\mathrm{L}}$ (fraction of open PSII centers), NPQ (non-photochemical quenching) and ETR (electron transport rate) [30] were measured under a PPFD of $300 \mu \mathrm{mol} \mathrm{m} \mathrm{m}^{-2} \mathrm{~s}^{-1}$ with external light source. Actinic light was provided by a halogen lamp (Schott KL 1500, Göttingen, Germany) through fiber optics. Light level was manually controlled. A micro quantum and thermo sensor on the leaf clip holder recorded the incident PPFD and leaf temperature.

\section{Data analysis}

Analysis of variance (ANOVA) between the parameters of plants under control, drought, heat and drought + heat stress of heat and drought were performed using SPSS 16.0 (SPSS Inc. Chicago, IL, USA).

\section{Results}

\section{Plant growth and leaf relative water content}

Plant height of 'Arvento' significantly decreased under drought stress and combined stress compared to control (Fig. 1a). The plant height of 'LA2093' was significantly lower under drought stress than heat stress (Fig. 1a). Combined stress had no significant effect on the plant height of 'LA1994', being the shortest of the three cultivars in all four treatments (Fig. 1a). Individual drought and heat stress significantly increased the internode length of 'LA2093' (Fig. 1b). The leaf number of 'LA1994' was significantly lower under drought stress and combined stress than control (Fig. 1c). The leaf angle of 'Arvento' significantly decreased under heat stress in comparison with control (Fig. 1d). In contrast to this the leaf angle of 'Arvento' and 'LA1994' significantly increased under drought and combined stress compared to control (Fig. 1d). For 'LA2093', the leaf angle of plants was significantly smaller under heat stress than combined stress (Fig. 1d). The leaf area was significantly lower under drought and combined stress than control (Fig. 1e). The leaf temperature of 'Arvento' was significantly higher during heat and combined stress than control and drought stress (Fig. 1f). For 'LA1994' and 'LA2093', the leaf temperatures of plants were significantly higher under stresses than control (Fig. 1f). In all cultivars, plants under drought and combined stress showed wilted stem and leaf and similar phenotype, while plants under heat stress did not show apparent damage compared to the control (Fig. 1g, h, i).

The shoot fresh weight of the three cultivars significantly decreased under drought and combined stress compared to control (Fig. 2a). The shoot dry weight of 'Arvento' significantly decreased under stresses (Fig. 2b). For 'LA1994' and 'LA2093', the shoot dry weight of plants was significantly smaller under drought and combined stress than control, while it was unaffected by heat stress alone (Fig. 2b).

The leaflets of plants under control and individual stresses recovered, while the leaflets under combined stress stayed wilted after being immersed with $\mathrm{ddH}_{2} \mathrm{O}$ (Fig. 3a, b, c). The relative water content of all cultivars significantly decreased under drought and combined stress in comparison with control, while it was unaffected by heat alone (Fig. 3d).

\section{Pigment content}

The Chl a and Chl b content in 'Arvento' significantly increased under drought and combined stress, while in 'LA1994' individual and combined stress significantly increased and decreased $\mathrm{Chl}$ a content, respectively (Fig. 4a, b). The change of Car content in 'Arvento' was the same as that of $\mathrm{Chl} \mathrm{a}$ and $\mathrm{Chl} \mathrm{b}$ content (Fig. 4c). The individual heat stress and combined stress significantly increased and decreased the Car content in leaves of 'LA2093', respectively (Fig. 4c). Chl a/b of leaves from 'Arvento' and 'LA1994' significantly decreased under single and combined stress in comparison with control (Fig. 4d). The chlorophyll composition was unaffected by the treatments in 'LA2093' (Fig. 4a, b, d).

\section{Stomatal characteristics}

The stomatal and pore length significantly decreased in all cultivars under drought and combined stress compared to control (Fig. 5a, c), while the stomatal width was unaffected by any stress (Fig. 5b). The pore width of 'LA1994' and 'LA2093' significantly increased under heat stress, while it decreased in 'LA1994' under the combined stress in comparison with control (Fig. 5d). Stomatal and pore area was significantly smaller than the control in 'Arvento' at combined stress and 'LA1994' and 'LA2093' under drought and combined stress (Fig. 5e, f). 

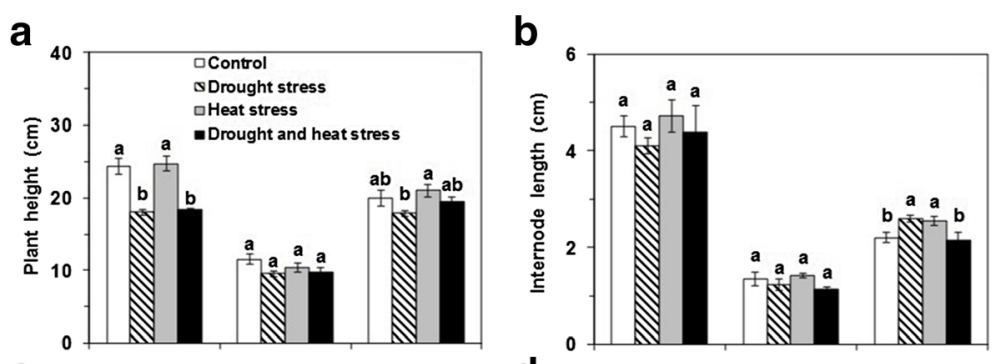

C
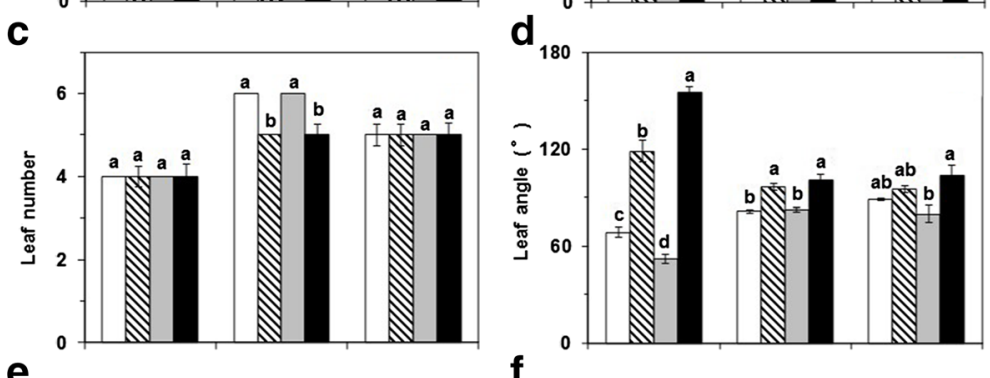

$\mathbf{f}$
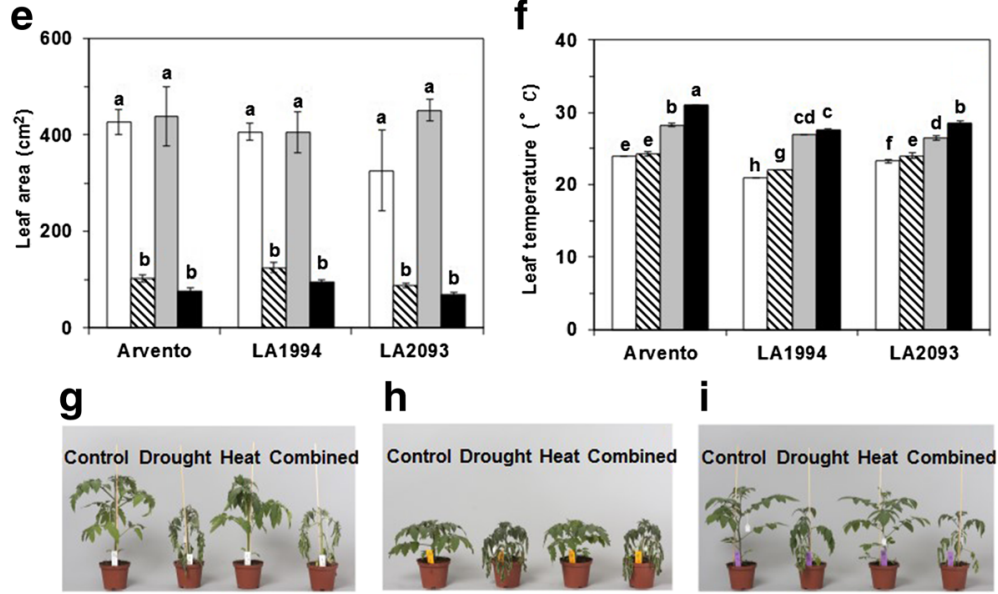

Fig. 1 Plant height and leaf growth parameters of the three tomato cultivars under four days of control, drought, heat and combined stress. Different sub-graphs represent $\mathbf{a}$ plant height, $\mathbf{b}$ internode length, $\mathbf{c}$ leaf number, $\mathbf{d}$ leaf angle, e leaf area, $\mathbf{f}$ leaf temperature of the three tomato cultivars and phenotypes of $\mathbf{g}$ 'Arvento', h 'LA1994' and i 'LA2093' under control, drought, heat and combined stress. The data represent mean values $\pm \operatorname{SE}(n=4)$. Different small letters above the bars indicate significant differences $(P<0.05)$

The pore area significantly increased under heat stress in 'LA1994' and 'LA2093' compared to control (Fig. 5f). The stomatal number was significantly higher than control under combined stress in 'LA1994' and under all stress treatments in 'LA2093' (Fig. 5g).

\section{Temperature response curves of gas exchange and carbohydrate content}

The $P_{\mathrm{N}}$ of 'Arvento' and 'LA2093' under combined stress significantly decreased already on day 2 compared to control irrespective of temperature, while the heat stress
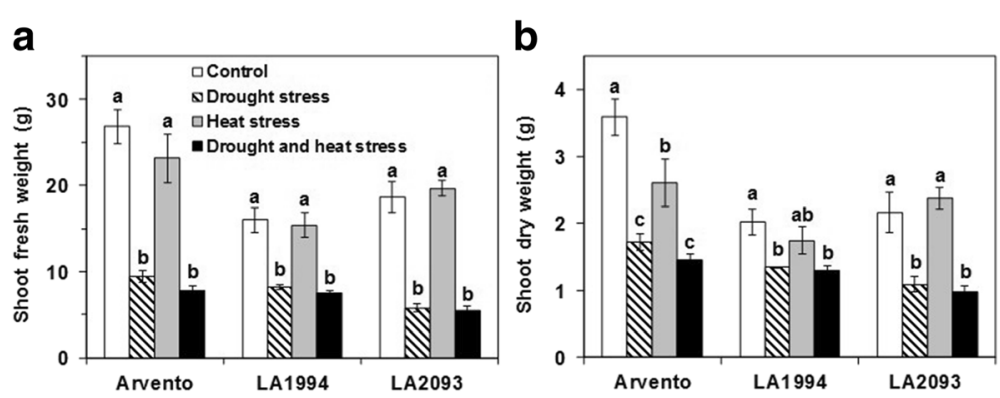

Fig. 2 a Shoot fresh weight and $\mathbf{b}$ shoot dry weight of the three tomato cultivars under four days of control, drought, heat and combined stress. The data represent mean values \pm SE $(n=4)$. Different small letters above the bars indicate significant differences $(P<0.05)$ 


\section{a}

b $\quad$ C

Control Drought Heat Combined Control Drought Heat CombinedControl Drought Heat Combined

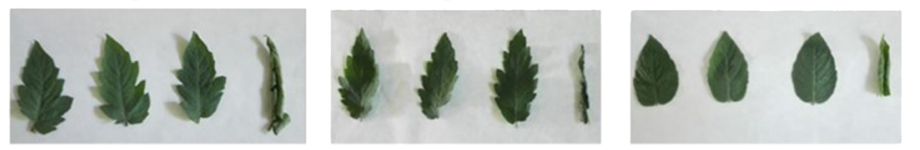

d

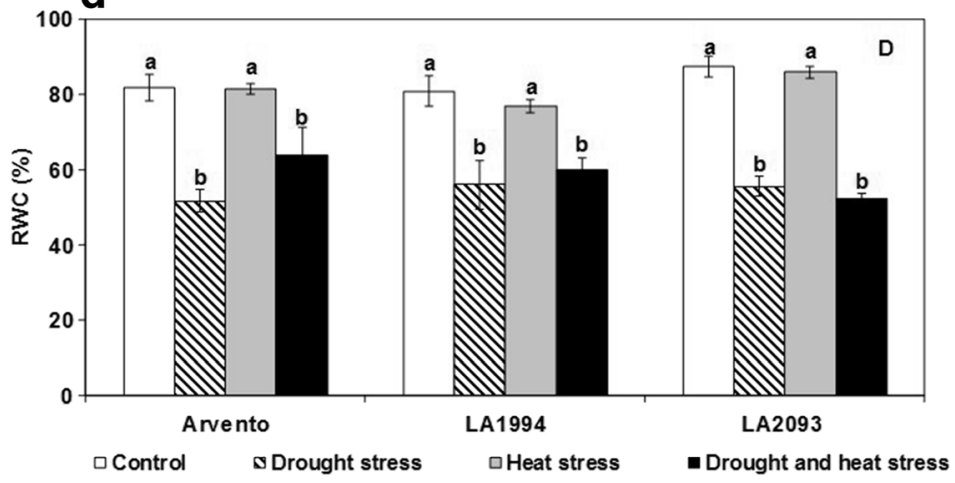

Fig. 3 Relative water content (RWC, \%) of the three tomato cultivars under four days of control, drought, heat and combined stress. Different sub-graphs represent leaflets after being immersed with $\mathrm{ddH}_{2} \mathrm{O}$ from a 'Arvento', $\mathbf{b}$ 'LA1994' and $\mathbf{c}$ ' $\mathrm{LA2093}$ ' and $\mathbf{d}$ RWC of the three tomatoes under control, drought, heat and combined stress. The data represent mean values \pm SE $(n=4)$. Different small letters above the bars indicate significant differences $(P<0.05)$

was not different from the control on day 4 (Fig. 6a, c). In the drought and combined stress treatments, $P_{\mathrm{N}}$ dropped to almost zero at most temperatures after four days in all three cultivars (Fig. 6a, b, c), which was accompanied with almost zero $g_{s}$ (Fig. 6d, e, f) and $E$ (Fig. 6g, h, i). The $g_{\mathrm{s}}$ of 'Arvento' and 'LA2093' under heat stress were respectively higher and lower than control at most temperatures, (Fig. 6d, f), while it was mostly unaffected in 'LA1994' (Fig. 6e). The $E$ of all cultivars followed the same patterns as $g_{s}$ (Fig. 6 g, h, i).
The glucose content of 'Arvento' was significantly higher under drought stress than control, while the glucose content significantly decreased in 'LA1994' under drought and combined stress and significantly increased in 'LA2093' under heat stress (Fig. 7a). The fructose content was significantly higher than control in 'Arvento' under individual drought and heat stress and in 'LA2093' under heat stress, but fructose content in 'LA1994' under all stresses was significantly lower than control (Fig. 7b). Compared to control, the sucrose
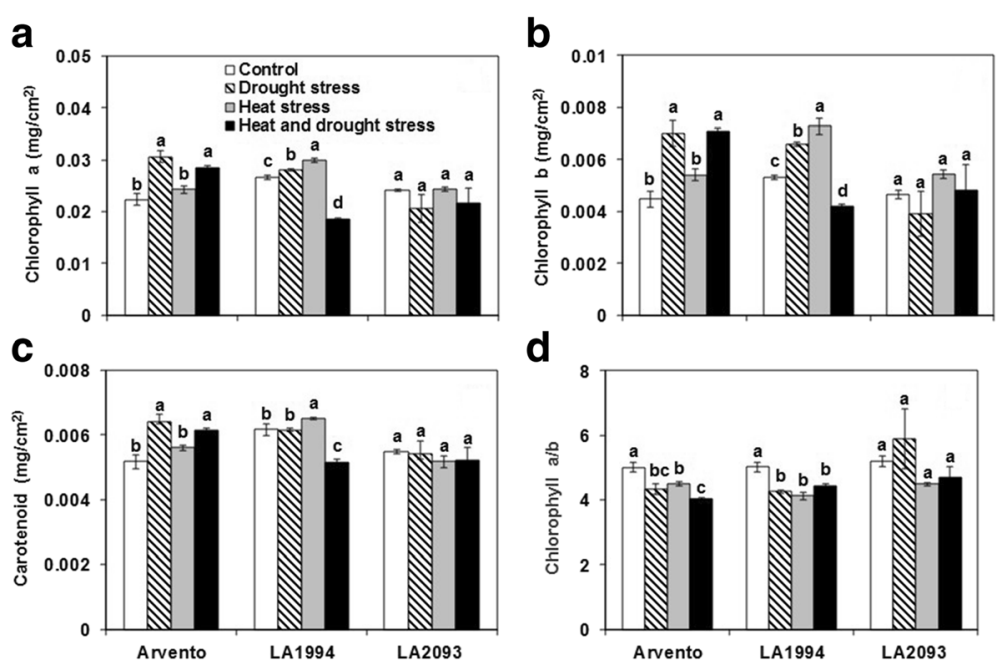

Fig. 4 Leaf pigment content per unit area of the three tomato cultivars under four days of control, drought, heat and combined stress. Different sub-graphs represent $\mathbf{a}$ chlorophyll a, $\mathbf{b}$ chlorophyll b, c carotenoid and $\mathbf{d}$ chlorophyll a/b. The data represent mean values $\pm \mathrm{SE}(n=4)$. Different small letters above the bars indicate significant differences $(P<0.05)$ 

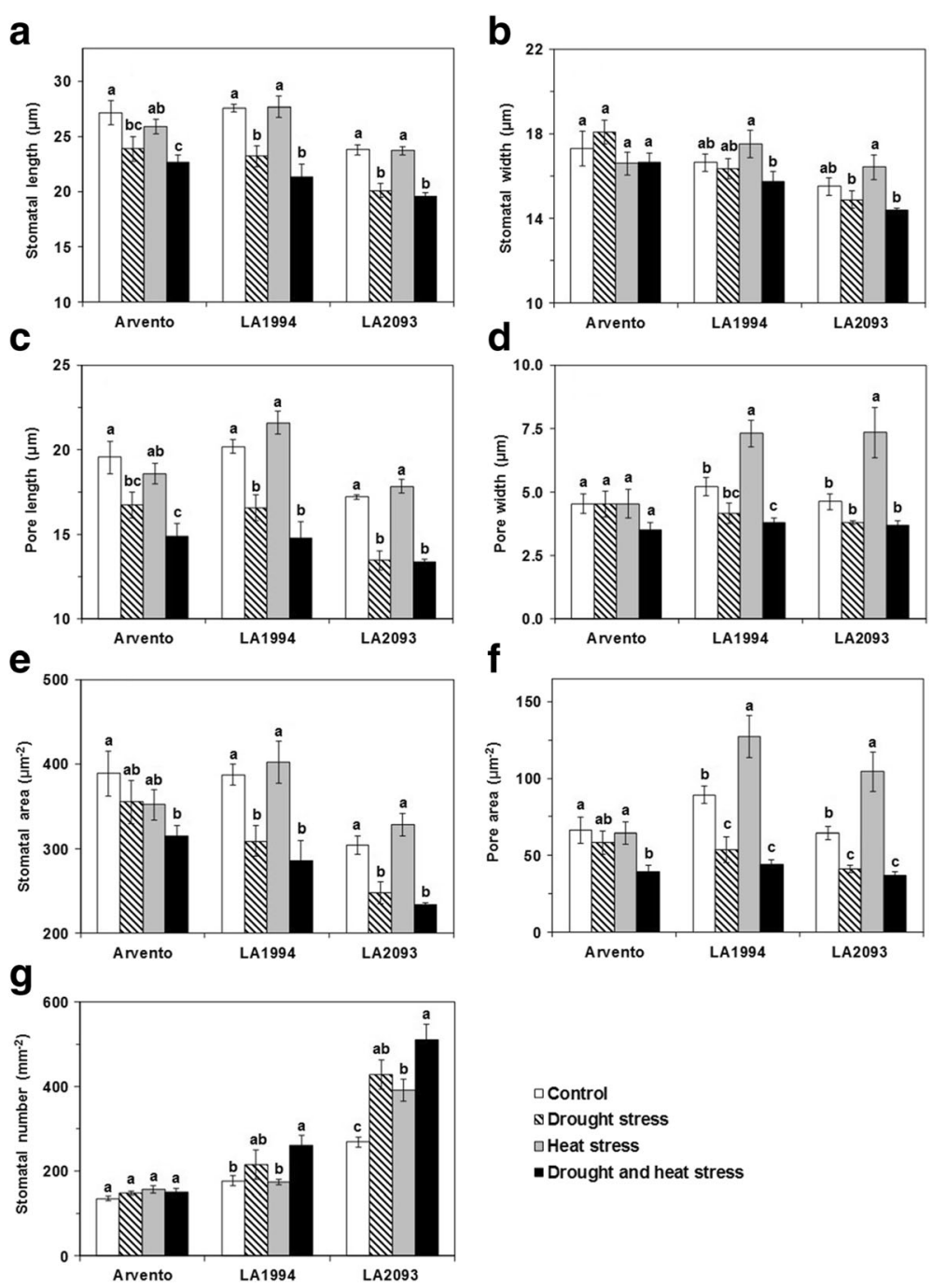

Fig. 5 Stomatal characteristics in the abaxial leaves of the three tomato cultivars under four days of control, drought, heat and combined stress. Different sub-graphs represent $\mathbf{a}$ stomatal length, $\mathbf{b}$ stomatal width, $\mathbf{c}$ pore length, $\mathbf{d}$ pore width, e stomatal area, $\mathbf{f}$ pore area and $\mathbf{g}$ stomatal number. The data represent mean values $\pm \operatorname{SE}(n=4)$. Different small letters above the bars indicate significant differences $(P<0.05)$

content of 'Arvento' significantly increased under all stresses, but significantly decreased in 'LA1994' and 'LA2093' under drought and combined stress (Fig. 7c). The sucrose content of 'LA2093' was significantly higher under heat stress than control (Fig. 7c). The starch content significantly decreased in three cultivars under all stresses compared to control, except for 'LA2093' under heat stress (Fig. 7d).

\section{Chlorophyll fluorescence}

The $F_{v} / F_{m}$ of 'LA1994' and 'LA2093' was significantly lower under combined stress than control (Fig. 8a). Compared to control, $\Phi_{\text {PSII }}$, ETR and $\mathrm{q}_{\mathrm{L}}$ of 'Arvento' significantly increased under heat stress, while they significantly decreased in 'LA1994' and 'LA2093' under drought and combined stress (Fig. 8b, c, d). NPQ significantly increased in 'Arvento' under drought stress but decreased under heat stress in comparison with control (Fig. 8e). For 'LA1994' and 'LA2093', NPQ significantly increased under drought and combined stress (Fig. 8e).

\section{Discussion}

Drought and heat stress has severely restricted world crop production, which has caused a big loss for agricultural economy [22, 34, 35]. The response of tomato plants to single drought or heat stress have been previously described extensively [4, 15-18].

When drought and heat was applied in combination, the response of plants could not be compared to the conclusions drawn from individual stress experiments for tobacco [19] and Arabidopsis [20, 21]. Compared to 

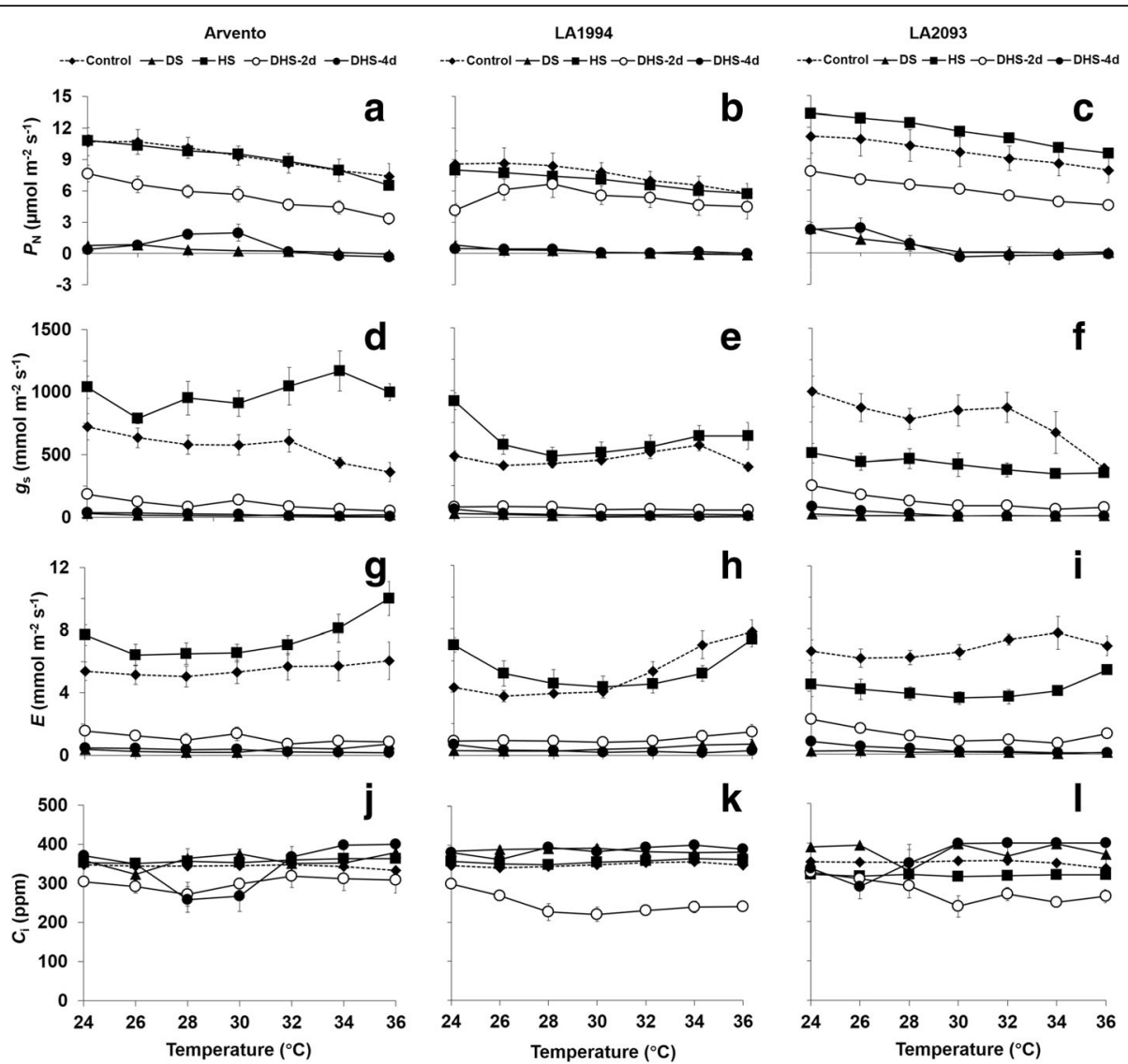

Fig. 6 Temperature response curve in the leaves of the three tomato cultivars under control, drought, heat and combined stress on day 4 and for the combined stress also on day 2. Different sub-graphs represent $\mathbf{a}, \mathbf{b}, \mathbf{c}$ net photosynthetic rate $\left(P_{\mathrm{N}}\right), \mathbf{d}, \mathbf{e}, \mathbf{f}$ stomatal conductance $\left(g_{5}\right), \mathbf{g}, \mathbf{h}, \mathbf{i}$ transpiration rate $(E)$ and $\mathbf{j}, \mathbf{k}$, I intracellular $\mathrm{CO}_{2}$ concentration $\left(C_{\mathrm{i}}\right)$. The data represent mean values $\pm \mathrm{SE}(n=4)$
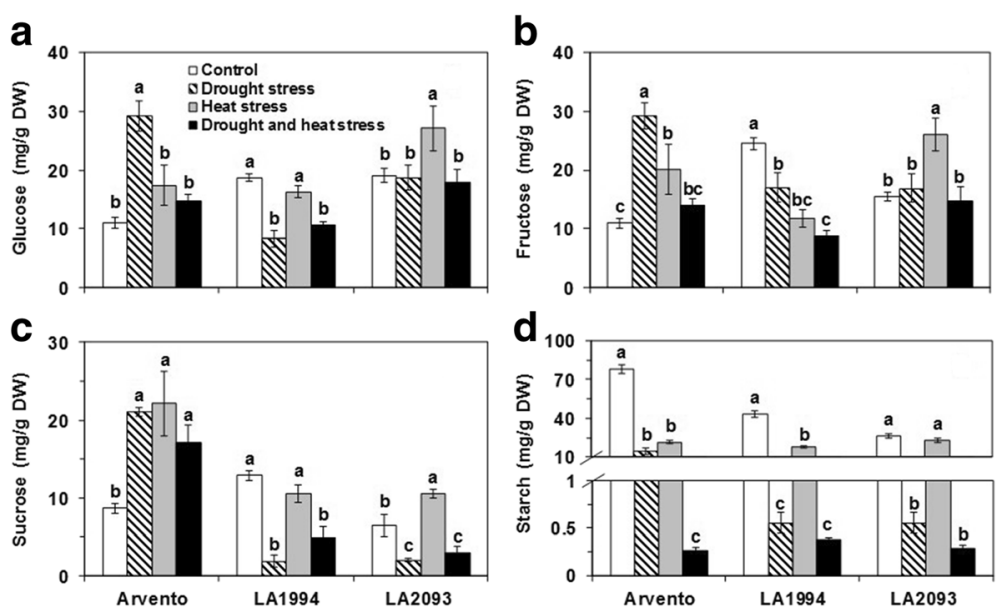

Fig. 7 Carbohydrates content in the leaves of the three tomato cultivars under four days of control, drought, heat and combined stress. Different sub-graphs represent $\mathbf{a}$ glucose, $\mathbf{b}$ fructose, $\mathbf{c}$ sucrose and $\mathbf{d}$ starch. The data represent mean values $\pm \operatorname{SE}(n=4)$. Different small letters above the bars indicate significant differences $(P<0.05)$ 

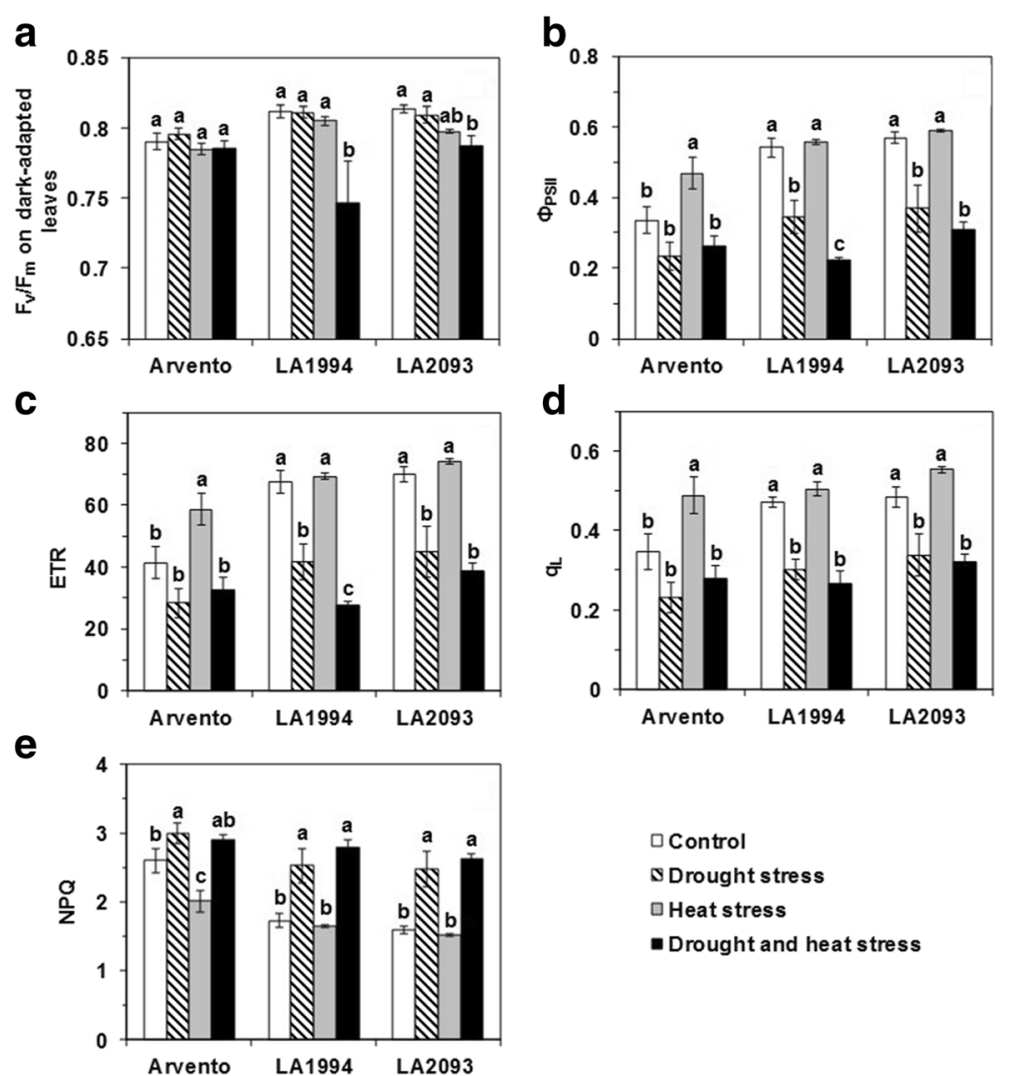

Fig. 8 Chlorophyll fluorescence measured at a PPFD of $300 \mu \mathrm{mol} \mathrm{m} \mathrm{m}^{-2}$ at room temperature in the three tomato cultivars under four days of control, drought, heat and combined stress. Different sub-graphs represent $\mathbf{a} F_{\mathrm{v}} / F_{\mathrm{m}}$ on dark-adapted leaves, $\mathbf{b}$ quantum efficiency of PSII ( $\left.\Phi_{\mathrm{PSII}}\right)$, c electron transport rate (ETR), $\mathbf{d}$ fraction of open PSII centers (q $\mathrm{q}_{\mathrm{L}}$ ) and $\mathbf{e}$ non-photochemical quenching (NPQ). The data represent mean values \pm SE $(n=4)$. Different small letters above the bars indicate significant differences $(P<0.05)$

control, the internode length of plants of 'LA2093' grown under combined stress was not affected, while it increased under individual drought and heat treatment. Similarly, the leaf angle of 'Arvento' under combined drought and heat stress was larger than control, while the leaf angle of the plants under individual drought and heat stress increased and decreased, respectively. These results partly confirmed that the effect of combined drought and heat stress to tomato differ from individual stress. This might be due to different, sometimes even opposing, signaling pathways induced by combined stress [7].

Combined drought and heat stress usually create more severe damage than individual stresses in a temperate annual/biannual plant community [36] and in crops such as barley [37] and chickpea [10]. The combination of drought and heat stress have potential negative interaction $[1,7,38]$. Barley at $36 / 32{ }^{\circ} \mathrm{C}$ (day/night) for seven days with the soil water content being $15 \%$ field capacity and chickpea at $32: 20{ }^{\circ} \mathrm{C}$ (maximum: minimum temperature) with $50 \%$ leaf water content were used to study the combined effect of drought and heat stress $[10,37]$. Even though emerging evidence show that plant responses to combined stresses are unique, plants exhibit shared responses which are common to individual stresses and stress combination [38]. Moreover, the combined stress does not always increase the damage on plants than single stress as shown in this study. The combination effect of drought and heat stress could be similar to single stress when one of the single stress played a predominant role on tomato. We found that heat stress did not damage the three tomato cultivars as most of the leaf physiological parameters showed no difference between tomatoes under control and heat stress, which was in accordance with the results of Nankishore and Farrell [39]. In contrast to the expected negative effect of stress combination on tomato growth, the combination of heat and salinity showed a remarkable protection level to tomatoes from salinity stress [23]. Similarly, drought stress played predominant role as indicated by significant damage on tomatoes caused by drought rather than heat. As a consequence, most of the responses of the three tomatoes including leaf area, shoot fresh and dry weight, leaf relative water content (RWC), stomatal and pore length and temperature response curve under combined stress were similar to 
single drought stress. As shown by Vile et al., [40], no specific trait was affected only by the combination of heat and drought among the traits investigated in Arabidopsis. Similarly, we found that the main responses caused by simultaneous occurrence of drought and heat stress were caused by single drought stress in tomatoes. For example, leaf area, shoot fresh and dry weight of all three cultivars under combined stress was similar to the drought treatment, and significantly lower than under control and heat treatment. The alteration of these three growth indexes coincided with the change of $P_{\mathrm{N}}$ due to the interconnection between growth/yield and photosynthesis [23]. There was independency between the mechanisms of plants in responsive to drought and heat stress in Arabidopsis [40]. Drought stress has been shown to inhibit photosynthesis mainly by the closure of stomata due to cellular water depletion and subsequent reduction of assimilate transport [25], which was also seen in our experiment. In contrast, heat stress affecting the $P_{\mathrm{N}}$ through the biochemical reactions of photosynthesis [26-28]. The drought treatment caused a considerably larger inhibition of $P_{\mathrm{N}}$ than the heat treatment in all three cultivars due to lower $g_{s}$. Therefore, drought and heat stress limit tomato photosynthesis and might ultimately decrease tomato yield. Drought and the combination of drought and heat stress caused $>80 \%$ reduction in photosynthesis in tobacco plants, while heat stress did not decrease photosynthesis [19], which was similar with our conclusion in tomatoes. In case of combined heat and drought stress differing in severity, the physiological responses of tomatoes are apparently determined by the most severe stress in this case drought stress, as concluded by Pandey et al. [38]. Drought stress caused a greater effect than heat stress on yield and seed-filling in chickpea [10]. Thus drought stress might cause more severe reduction in tomato yield than heat stress as a consequence of the decreased $P_{\mathrm{N}}$, leaf area, shoot fresh and dry weight. However, the effect of single and combined stress on tomato flowering, fruit set and yield need further research.

Although the three cultivars maintained high $P_{\mathrm{N}}$ during heat stress, the stomatal regulation differed. 'Arvento' had higher $g_{\mathrm{s}}$, 'LA1994' was unaffected while 'LA2093' showed generally a lower $g_{\mathrm{s}}$ during heat stress. While neither 'Arvento' nor 'LA1994' showed a decrease in $C_{\mathrm{i}}$ during heat stress, the low $\mathrm{g}_{\mathrm{s}}$ in 'LA2093' decreased $C_{\mathrm{i}}$ even though a high $P_{\mathrm{N}}$ could be maintained. As soon as drought was one of the stresses, $g_{\mathrm{s}}$ drastically decreased. A decrease in $P_{\mathrm{N}}$ could be the consequence of stomatal limitation where a decreased $g_{\mathrm{s}}$ was accompanied by declining $C_{\mathrm{i}}$ or non-stomatal factors with no difference in $C_{\mathrm{i}}$ [41]. After two days of combined heat and drought stress, $P_{\mathrm{N}}$ decreased due to stomatal limitation in all three cultivars. After four days of single drought or combined stress, however, $P_{\mathrm{N}}$ was reduced to almost zero due to biochemical limitations since $C_{\mathrm{i}}$ was unaffected at most temperatures, despite $g_{\mathrm{s}}<50 \mathrm{mmol} \mathrm{m} \mathrm{m}^{-2} \mathrm{~s}^{-1}$. The only deviation was in 'Arvento' at $28-30{ }^{\circ} \mathrm{C}$ and 'LA2093' at 24$28{ }^{\circ} \mathrm{C}$, where low $P_{\mathrm{N}}$ was still maintained after four days of combined stress, as reflected in a lowering of $C_{\mathrm{i}}$. The $P_{\mathrm{N}}$ of tomatoes under control, heat stress for four days and combined stress for two days decreased with increased temperature, indicating that the high temperature adversely affected the $P_{\mathrm{N}}$ of tomatoes, when there was no stress or the stress did not completely restrict the $P_{\mathrm{N}}$. Sustained high $P_{\mathrm{N}}$ in heat tolerant cultivars required high $g_{\mathrm{s}}$, which allowed high $E$ and better cooling of the leaves than heat susceptible cultivars in wheat [28] and tomato [4]. We found that the cultivars differing in heat sensitivity did not show difference in the sensitivity of combined stress, which indicated that selection for one type of tolerance might not improve the tolerance to combined stress.

Sucrose, the primary end product of photosynthesis, is translocated from source leaf to sink organ through the phloem [42]. Sucrose content in 'LA1994' and 'LA2093' under single drought and combined stress decreased as compared to control, which might be due to lower $P_{\mathrm{N}}$ and reduced photosynthetic gain. However, sucrose in 'Arvento' leaf under stress accumulated, probably as sugar production rate in leaf exceed the export rate due to insufficient sink activity [43]. This can in turn lead to a decrease in $P_{\mathrm{N}}$ in 'Arvento' as a consequence of feedback inhibition and attenuate the source-link balance [43]. Arabidopsis subjected to combination of drought and heat stress accumulated sucrose that played a role as the major osmoprotectant [20], indicating that sucrose might play function as osmoprotectant in 'Arvento' under stress and sucrose content could be an important selection indicator for plants treated under drought and heat stress. Another indicator could be starch content, since only 'Arvento' had lower starch content under single heat stress as compared to control. Besides, the starch content of 'Arvento' were significantly higher than 'LA1994' and 'LA2093' under single drought stress. These indicated that 'Arvento' had better drought tolerance than 'LA1994' and 'LA2093', while 'LA1994' and 'LA2093' had better heat tolerance than 'Arvento'. Combined stress tolerance in maize was distinct from individual stress tolerance in maize [44]. In contrast, the three tomato genotypes showed identical tolerance pattern to the combined stresses even though they showed different tolerance to single stress in this study. Single drought and combined stress induced premature senescence in the photosynthetic source leaf as indicated by wilting leaf, low $P_{\mathrm{N}}$ and reduced shoot weight. This might be followed by reducing the number and growth of the harvestable sink fruit through affecting the transport of assimilate [45] to avoid the feedback inhibition 
of leaf photosynthesis by coordinating the transport of assimilate between source leaf and fruit sink, which might delay leaf senescence [46].

Chlorophyll content strongly depends on the species' physiological responses and their ability to tolerate stress [3]. Chlorophyll content is one of the most effective indicators for heat and drought tolerance identification of tomatoes [39]. High temperature could increase the chlorophyll content of heattolerant tomato [4]. Drought stress caused an increase in chlorophyll content in the upper leaves of tobacco plants, while the stress accelerated senescence in the lower leaves [47]. These explained why the chlorophyll content of the first fully expanded leaf increased in 'LA1994' under heat stress and in 'Arvento' and 'LA1994' under drought stress. In a previous study, the heat-tolerant tomato line had a higher stomatal number, bigger stomatal and pore size and a relatively lower leaf temperature under heat stress than control due to increased cooling capacity [4]. Accordingly, heat treatment induced bigger pore width and area in two heat-tolerant tomatoes in this study. However, stomatal closure is one of the first steps in response to drought stress and it relates to dehydration avoidance by reducing water loss and maintaining water status during unfavorable conditions [48]. This explained the decreased length and area of stomata and pore under individual drought and combined drought and heat stress.

Leaf relative water content (RWC) was established as an indicator of water status balance and plants with different leaf RWC could indicate a corresponding difference in leaf hydration, leaf water deficit and physiological water status $[3,49]$. Decrease in RWC was a main factor causing decreased growth responding to osmotic stress in plants [50]. Under drought stress, sensitive pea genotypes were more affected by the decline in RWC than tolerant genotypes [51]. However, in our study, RWC decreased but with no significant difference between the tomato cultivars under drought and combined stress. This suggested that the three cultivars had similar sensitivity when subjected to drought and combined stress.

Short-term drought did not affect the efficiency of primary photochemical processes of PSII or the associated $\mathrm{F}_{\mathrm{v}} / \mathrm{F}_{\mathrm{m}}$ [52]. Photorespiration steps in the sink for ATP and NADPH protect PSII from damage when $g_{\mathrm{s}}$ decreases [30], which explained why $\mathrm{F}_{\mathrm{v}} / \mathrm{F}_{\mathrm{m}}$ of three cultivars was not affected by drought treatment. Therefore, the $F_{v} / F_{m}$ in vivo is not an effective parameter for distinguishing tomato genotypic variation under drought stress even though the $F_{v} / F_{m}$ in vitro was effective in a previous study [39]. Noteworthy, in this study, combined drought and heat treatment decreased the $F_{v} / F_{m}$ of two heat-tolerant tomatoes even though the $F_{v} / F_{m}$ of two heat-tolerant tomatoes under individual stress was not affected. This proved that the combination of heat and drought could aggravate the damage to tomatoes to some extent in accordance with the conclusion from Dreesen et al. [36] and Rollins et al. [37]. Moreover, we noticed a significant decrease in $\Phi_{\mathrm{PSII}}, \mathrm{ETR}, \mathrm{q}_{\mathrm{L}}$ and increase in NPQ of two heat-tolerant tomatoes under drought and combined stress. This indicated that the severe stomatal closure after four days of drought related stress reduced the $\mathrm{CO}_{2}$ supply to chloroplasts [53]. Not only did $\mathrm{P}_{\mathrm{N}}$ of the heat-tolerant tomatoes decrease, but also ETR, which was compensated by increased heat dissipation through NPQ protecting PSII from stress induced photoinhibition in drought stress alone, while the combined drought and heat stress was severe enough to damage PSII as indicated by the lower $F_{v} / F_{m}$ in the two cultivars. By contrast, chlorophyll fluorescence parameters except NPQ was not affected in 'Arvento' under drought and combined stress.

\section{Conclusions}

This study was designed to clarify the physiological response of tomato plants to combined drought and heat stress, two of the most common abiotic stresses that usually act together. The tomato 'LA1994' and 'LA2093' could tolerate heat stress better than 'Arvento' as indicated by significant decreases in shoot dry weight, chlorophyll a, carotenoid and starch content and NPQ only in 'Arvento' under heat treatment. By contrast, the two heat-tolerant tomatoes were more affected by drought stress compared to 'Arvento' as indicated by small stomatal area and pore area, decreased sucrose content, $\Phi_{\mathrm{PSII}}$, ETR and $\mathrm{q}_{\mathrm{L}}$ in 'LA1994' and 'LA2093' under drought treatment. Even though only 'LA1994' and 'LA2093' showed decreased $F_{v} / F_{m}$, $\Phi_{\text {PSII }}$, ETR and $\mathrm{q}_{\mathrm{L}}$ under combined stress, the three tomato cultivars showed similar response when subjected to the combination of drought and heat stress as shown by other physiological parameters. The cultivars differing in heat sensitivity did not show difference in the combined stress sensitivity, which indicated that selection for one type of tolerance might not improve the combined stress tolerance. Simultaneous application of heat and drought to the three tomato cultivars reveals similar responses mainly in plant growth, photosynthesis and chlorophyll fluorescence to the application of single drought stress. Therefore, the responses of tomato to combined heat and drought are predominantly controlled by water limitation instead of heat stress in this study. However, the effect of stress especially for combined stress on tomato fruit setting and yield need further studies. 


\section{Abbreviations}

Car: Carotenoid; Chl a: Chlorophyll a; Chl b: Chlorophyll b; $\mathrm{C}_{\mathrm{i}}$ : Intracellular $\mathrm{CO}_{2}$ concentration; DW: Dry weight; E: Transpiration rate; ETR: Electron transport rate; $F_{\mathrm{v}} / F_{\mathrm{m}}$ : Maximum potential quantum efficiency of photosystem II; FW: Fresh weight; $g_{s}$ : Stomatal conductance; NPQ: Non-photochemical quenching; $P_{\mathrm{N}}$ : Net photosynthetic rate; PPFD: Photosynthetic photon flux density; PSII: Photosystem II; qL: Fraction of open PSII centers; RH: Relative humidity; TW: Turgid weight; VPD: Vapor pressure deficit; $\Phi_{\text {PsII: }}$ Quantum yield of photosystem $\|$

\section{Acknowledgements}

The authors thank Dr. Katrine H. Kjær, Ms. Ruth Nielsen, Ms. Helle Kjaersgaard and Mr. Kaj Ole Dideriksen for their assistance during the experiments.

\section{Funding}

The funders had no role in the experiment design, data analysis, decision to publish or preparation of the manuscript. We acknowledge the funding from Natural Science Foundation of Youth in Jiangsu Province (BK20160579, BK20140739), Natural Science Foundation of China (31601745), Basic Scientific Research Project in Jiangsu Academy of Agricultural Science [ZX(15)2003] and ERDF EU project GreenGrowing.

\section{Availability of data and materials}

The datasets during or analyzed during the current study available from the corresponding author on reasonable request.

\section{Authors' contributions}

TZ and ZW participated in the conception of this study and design of the experiment. RZ and XY performed the experiment, analysed the data and wrote the manuscript. $\mathrm{CO}$ and ER assisted in the experiment design and revision of the manuscript. LZ, YW and WY assisted in the data analysis. All authors have read the manuscript, given comments and approved the final version of the manuscript.

\section{Competing interests}

The authors declare that they have no conflict of interest.

\section{Consent for publication}

Not applicable.

\section{Ethics approval and consent to participate}

Not applicable.

\section{Deposition of data}

Not applicable.

\section{Author details}

${ }^{1}$ Institute of Vegetable Crop, Jiangsu Academy of Agricultural Science, Nanjing, Jiangsu, China. ${ }^{2}$ Jiangsu Key Laboratory for Horticultural Crop Genetic Improvement, Nanjing, Jiangsu, China. ${ }^{3}$ College of Horticulture, Nanjing Agricultural University, Nanjing, Jiangsu, China. ${ }^{4}$ Department of Food Science, Aarhus University, Årslev, Denmark. ${ }^{5}$ Department of Plant and Environmental Sciences, University of Copenhagen, Taastrup, Denmark.

Received: 13 September 2016 Accepted: 11 January 2017

Published online: 25 January 2017

\section{References}

1. Mittler R. Abiotic stress, the field environment and stress combination Trends Plant Sci. 2006;11:15-9.

2. Aprile A, Havlickova L, Panna R, Marè C, Borrelli GM, Marone D, et al. Different stress responsive strategies to drought and heat in two durum wheat cultivars with contrasting water use efficiency. BMC Genomics. 2013; 14:821-38.

3. Siddiqui MH, Al-Khaishany MY, Al-Qutami MA, Al-Whaibi MH, Grover A, Ali HM, et al. Morphological and physiological characterization of different genotypes of faba bean under heat stress. Saudi J Biol Sci. 2015;22:656-63.

4. Zhou R, Yu X, Kjær KH, Rosenqvist E, Ottosen CO, Wu Z. Screening and validation of tomato genotypes under heat stress using $F_{v} / F_{m}$ to reveal the physiological mechanism of heat tolerance. Environ Exp Bot. 2015;118:1-11.
5. Hirayama T, Shinozaki K. Research on plant abiotic stress responses in the post-genome era: past, present and future. Plant J. 2010;61:1041-52.

6. Chew YH, Halliday KJ. A stress-free walk from Arabidopsis to crops. Curr Opin Biotech. 2011:22:281-6.

7. Suzuki N, Rivero RM, Shulaev V, Blumwald E, Mittler R. Abiotic and biotic stress combinations. New Phytol. 2014;203:32-43.

8. Boyer JS. Plant productivity and environment. Science. 1982;218:443-8.

9. Lipiec J, Doussan C, Nosalewicz A, Kondracka K. Effect of drought and heat stresses on plant growth and yield: a review. Int Agrophys. 2013;27:463-77.

10. Awasthi R, Kaushal N, Vadez V, Turner NC, Berger J, Siddique KHM, et al. Individual and combined effects of transient drought and heat stress on carbon assimilation and seed filling in chickpea. Funct Plant Biol. 2014;41: 1148-67.

11. Seki M, Umezawa T, Urano K, Shinozaki K. Regulatory metabolic networks in drought stress responses. Curr Opin Plant Bio. 2007:10:296-302.

12. Vadez V, Berger JD, Warkentin T, Asseng S, Ratnakumar P, Rao KPC, et al. Adaptation of grain legumes to climate change: a review. Agron Sustain Dev. 2012;32:31-44.

13. Hall AE. In: Janick J, editor. Breeding for heat tolerance: plant breeding reviews. USA: Wiley; 1992. p. 129-68.

14. Ahuja I, de Vos RC, Bones AM, Hall RD. Plant molecular stress responses face climate change. Trends Plant Sci. 2010;15:664-74.

15. Camejo D, Rodríguez P, Morales MA, Dell'Amico JM, Torrecillas A, Alarcón JJ. High temperature effects on photosynthetic activity of two tomato cultivars with different heat susceptibility. J Plant Physiol. 2005;162:281-9.

16. Camejo D, Jiménez A, Alarcón JJ, Torres W, Gómez JM, Sevilla F. Changes in photosynthetic parameters and antioxidant activities following heat-shock treatment in tomato plants. Funct Plant Biol. 2006;33:177-87.

17. Patanè C. Leaf area index, leaf transpiration and stomatal conductance as affected by soil water deficit and VPD in processing tomato in semi arid mediterranean climate. J Agron Crop Sci. 2011;197:165-76.

18. Mishra KB, lannacone R, Petrozza A, Mishra A, Armentano N, Vecchia GL, et al. Engineered drought tolerance in tomato plants is reflected in chlorophyll fluorescence emission. Plant Sci. 2012:182:79-86.

19. Rizhsky L, Liang H, Mittler R. The combined effect of drought stress and heat shock on gene expression in tobacco. Plant Physiol. 2002;130:1143-51.

20. Rizhsky L, Liang H, Shuman J, Shulaev V, Davletova S, Mittler R. When defense pathways collide: the response of Arabidopsis to a combination of drought and heat stress. Plant Physiol. 2004;134:1683-96.

21. Prasch CM, Sonnewald U. Simultaneous application of heat, drought, and virus to Arabidopsis plants reveals significant shifts in signaling networks. Plant Physiol. 2013:162:1849-66.

22. Grigorova B, Vasevam II, Demirevska K, Feller U. Expression of selected heat shock proteins after individually applied and combined drought and heat stress. Acta Physiol Plant. 2011;33:2041-9.

23. Rivero RM, Mestre TC, Mittler RON, Rubio F, Garcia-Sanchez F, Martinez V. The combined effect of salinity and heat reveals a specific physiological, biochemical and molecular response in tomato plants. Plant Cell Environ. 2014:37:1059-73.

24. Ashoub A, Baeumlisberger M, Neupaertl M, Karas M, Brüggemann W. Characterization of common and distinctive adjustments of wild barley leaf proteome under drought acclimation, heat stress and their combination. Plant Mol Biol. 2015:87:459-71.

25. Chaves MM, Flexas J, Pinheiro C. Photosynthesis under drought and salt stress: regulation mechanisms from whole plant to cell. Ann Bot. 2009;103: $551-60$

26. Havaux I. Rapid photosynthetic adaptation to heat stress triggered in potato leaves by moderately elevated temperatures. Plant Cell Environ. 1993;16: 461-7.

27. Allakhverdiev SI, Hayashi H, Nishiyama Y, Ivanov AG, Aliev JA, Klimov W, et al. Glycinebetaine protects the D1/D2/Cytb559 complex of photosystem II against photo-induced and heat-induced inactivation. J Plant Physiol. 2003;160:41-9.

28. Sharma DK, Andersen SB, Ottosen CO, Rosenqvist E. Wheat cultivars selected for high $F_{v} / F_{m}$ under heat stress maintain high photosynthesis, total chlorophyll, stomatal conductance, transpiration and dry matter. Physiol Plant. 2015;153:284-98.

29. Cajánek M, Štroch M, Lachetová I, Kalina J, Spunda V. Characterization of the photosystem II inactivation of heat-stressed barley leaves as monitored by the various parameters of chlorophyll a fluorescence and delayed fluorescence. J Photochem Photobiol B. 1998;47:39-45. 
30. Baker NR, Rosenqvist E. Applications of chlorophyll fluorescence can improve crop production strategies: an examination of future possibilities. J Exp Bot. 2004;55:1607-21.

31. Sharma DK, Andersen SB, Ottosen CO, Rosenqvist E. Phenotyping of wheat cultivars for heat tolerance using chlorophyll a fluorescence. Funct Plant Biol. 2012;39:936-47.

32. Wintermans J, De Mots A. Spectrophotometric characteristics of chlorophylls $a$ and $b$ and their phenophytins in ethanol. Biochim Biophys Acta. 1965;109: 448-53.

33. Giday $\mathrm{H}$, Kjaer KH, Fanourakis D, Ottosen CO. Smaller stomata require less severe leaf drying to close: a case study in Rosa hydrida. J Plant Physiol. 2013;170:1309-16.

34. Lobell DB, Schlenker W, Costa-Roberts J. Climate trends and global crop production since 1980. Science. 2011;333:616-20.

35. Chen J, Xu W, Velten J, Xin Z, Stout J. Characterization of maize inbred lines for drought and heat tolerance. J Soil Water Conserv. 2012;67:354-64.

36. Dreesen FE, de Boeck HJ, Janssens IA, Nijs I. Summer heat and drought extremes trigger unexpected changes in productivity of a temperate annual/biannual plant community. Environ Exp Bot. 2012;79:21-30.

37. Rollins JA, Habte E, Templer SE, Colby T, Schmidt J, von Korff M. Leaf proteome alterations in the context of physiological and morphological responses to drought and heat stress in barley (Hordeum vulgare L.) J Exp Bot. 2013:64:3201-12.

38. Pandey P, Ramegowda V, Senthilkumar M. Shared and unique responses of plants to multiple individual stresses and stress combinations: physiological and molecular mechanisms. Front Plant Sci. 2015;6:723-36.

39. Nankishore A, Farrell AD. The response of contrasting tomato genotypes to combined heat and drought stress. J Plant Physiol. 2016;202:75-82.

40. Vile D, Pervent M, Belluau M, Vasseur F, Bresson J, Muller B, et al. Arabidopsis growth under prolonged high temperature and water deficit: independent or interactive effects? Plant Cell Environ. 2012;35:702-18.

41. Von Caemmerer SV, Farquhar GD. Some relationships between the biochemistry of photosynthesis and the gas exchange of leaves. Planta. 1981;153:376-87.

42. Lalonde S, Boles E, Hellmann H, Barker L, Patrick JW, Frommer WB, et al. The dual function of sugar carriers: transport and sugar sensing. Plant Cell. 1999; 11:707-26.

43. lii WWA, Muller O, Cohu CM, Demmig-Adams B. Photosystem II efficiency and non-photochemical fluorescence quenching in the context of sourcesink balance: non-photochemical quenching and energy dissipation in plants, algae and cyanobacteria. Netherlands: Springer; 2014. p. 503-29.

44. Cairns JE, Crossa J, Zaidi PH, Grudloyma P, Sanchez C, Araus JL, et al. Identification of drought, heat, and combined drought and heat tolerant donors in maize. Crop Sci. 2013;53:1335-46.

45. Albacete AA, Martínez-Andújar C, Pérez-Alfocea F. Hormonal and metabolic regulation of source-sink relations under salinity and drought: from plant survival to crop yield stability. Biotechnol Adv. 2014;32:12-30.

46. Pérez-Alfocea F, Albacete A, Ghanem ME, Dodd LC. Hormonal regulation of source-sink relations to maintain crop productivity under salinity: a case study of root-to-root signalling in tomato. Funct Plant Bio. 2010;37:592-603.

47. Hana M, Marie H, Jana D, Veronika T, Ondřej N, Zuzana L, et al. Enhanced drought and heat stress tolerance of tobacco plants with ectopically enhanced cytokinin oxidase/dehydrogenase gene expression. J Exp Bot. 2013;64:2805-15

48. Stoddard FL, Balko C, Erskine W, Khan HR, Link W, Sarker A. Screening techniques and sources of resistance to abiotic stresses in cool-season food legumes. Euphytica. 2006;147:167-86.

49. Sekmen AH, Ozgur R, Uzilday B, Turkan I. Reactive oxygen species scavenging capacities of cotton (Gossypium hirsutum) cultivars under combined drought and heat induced oxidative stress. Environ Exp Bot. 2014:99:141-9.

50. Alexieva V, Sergiev I, Mapelli S, Karanov E. The effect of drought and ultraviolet radiation on growth and stress markers in pea and wheat. Plant Cell Environ. 2001;24:1337-44.

51. Upreti KK, Murti GSR, Bhatt RM. Response of pea cultivars to water stress: changes in morpho-physiological characters, endogenous hormones and yield. Veg Sci. 2000;27:57-61

52. Castonguay $Y$, Markhart AH. Saturated rates of photosynthesis in waterstressed leaves of common bean and tepary bean. Crop Sci. 1991;31:1605-11.

53. Ort DR, Baker NR. A photoprotective role for $\mathrm{O}_{2}$ as an alternative electron sink in photosynthesis? Curr Opin Plant Biol. 2002;5:193-8.

\section{Submit your next manuscript to BioMed Central and we will help you at every step:}

- We accept pre-submission inquiries

- Our selector tool helps you to find the most relevant journal

- We provide round the clock customer support

- Convenient online submission

- Thorough peer review

- Inclusion in PubMed and all major indexing services

- Maximum visibility for your research

Submit your manuscript at www.biomedcentral.com/submit
Biomed Central 